\title{
Research on Azadirachta indica: A scientometric assessment of global publications output during 1997-2016
}

\author{
B. M. Gupta, K. K. Mueen Ahmed ${ }^{1}$
}

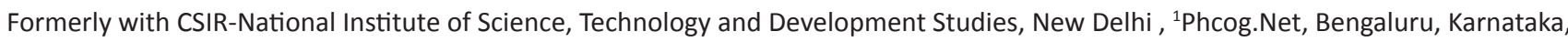

India

\begin{abstract}
Aim: The present study aimed to perform scientometric assessment of global publications output of research on Azadirachta indica during 1997-2016.

Methodology: The present study examined 4900 global publications on $A$. indica, as indexed and covered in international Scopus database during 1997-2016 with a view to understanding their growth rate, global publication share, citation impact, international collaborative papers share, distribution of publications by broad subjects, productivity and citation profile of top organizations and authors, preferred media of communication, and bibliographic characteristics of high cited papers.

Results: The global publications registered $7.61 \%$ annual average growth rate, and its citation impact averaged to 13.91 citations per paper. The global share of top 10 countries ranged from $1.91 \%$ to $31.04 \%$, with the largest share (53.49\%) from India, followed by Brazil (6.12\%), USA $(6.02 \%)$, etc., About $86.82 \%$ and $85.81 \%$ of the cumulative global publication and citation share comes from top 10 countries during 1997-2016. The cumulative global share of top 10 countries increased from $85.89 \%$ to $86.35 \%$ from $1997-2006$ to $2007-$ 2017. Only top three countries registered relative citation index above the world average of 1.0: UK (1.95), USA (1.71), and Germany (1.42) during 1997-2016. Agricultural and biological sciences contributed the largest global publications share of $48.41 \%$, followed by pharmacology, toxicology and pharmaceutics $(22.04 \%)$, biochemistry, genetics and molecular biology $(17.35 \%)$, medicine $(16.80 \%)$, environmental science $(13.39 \%)$, and other three sub-fields contribution varying from $4.90 \%$ to $8.22 \%$ during $1997-2016$. Eight hundred and forty-eight global organizations and 1589 authors participated in global $A$. indica research, of which the 25 most productive global organizations and authors together contributed $20.65 \%$ and $8.92 \%$ global publication share and $22.43 \%$ and $12.66 \%$ global citation share, respectively, during $1997-2016$. Among 4387 journal papers (in 959 journals) in global $A$. indica research, the top 20 most productive journals together contributed 43.63\% global share of total journal publication output during 1997-2016.

Conclusion: Totally, 78 publications were found to be high cited, as they registered citations from 100 to 1441 during $1997-2016$ and they together received 18,498 citations, averaging to 237.15 citations per paper.
\end{abstract}

Keywords: Azadirachta indica, bibliometrics, global research output, medicinal plant, scientometrics

Address for correspondence: Dr. K. K. Mueen Ahmed, Phcog.Net No. 9, Wheeler Road Extn. St. Thomas Town, Bengaluru, India.

E-mail: mueen.ahmed@gmail.com

\begin{tabular}{|l|l|}
\hline \multicolumn{2}{|c|}{ Access this article online } \\
\hline Quick Response Code: & Website: \\
\hline & www.jpionline.org \\
\cline { 2 - 2 } & DOI: \\
\hline
\end{tabular}

This is an open access journal, and articles are distributed under the terms of the Creative Commons Attribution-NonCommercial-ShareAlike 4.0 License, which allows others to remix, tweak, and build upon the work non-commercially, as long as appropriate credit is given and the new creations are licensed under the identical terms.

For reprints contact: reprints@medknow.com

How to cite this article: Gupta BM, Mueen Ahmed KK. Research on Azadirachta indica: A scientometric assessment of global publications output during 1997-2016. Int J Pharma Investig 2018;8:164-72. 


\section{INTRODUCTION}

For centuries, agents derived from natural sources, especially plants have been the primary source of medicine. Neem, also referred to as Azadirachta indica is one such plant that has been so named because it provides freedom from all diseases and used for thousands of years in Indian and African continents. ${ }^{[1]}$ The United States has also recognized the significance of research on neem and published a report entitled "Neem-a tree for solving global problems."[2]

A. indica A. Juss (Neem) is a tropical evergreen tree (Fam. Meliacae; Subfam. Melioideae) has universally been accepted as a wonder tree because of its diverse utility and multitude of human benefits in various fields. Multidirectional therapeutic uses of neem have been known in India since the Vedic times. Different parts of the plant including flowers, leaves, seeds, and bark have been used to treat both acute and chronic human diseases; and used as insecticide; antimicrobial, larvicidal, antimalarial, antibacterial, antiviral, and spermicidal. It is widely used also for its cosmetic, medicinal, and agricultural uses. ${ }^{[3]}$

A. indica, commonly known as neem, has attracted worldwide prominence in recent years. Neem has been extensively used in Ayurveda, Unani, and Homoeopathic medicine and has become a cynosure of modern medicine. More than 140 compounds have been isolated from different parts of neem. All parts of the neem tree have been used conventionally for the treatment of inflammation, infections, fever, skin diseases, and dental disorders. ${ }^{[4]}$

Different parts of the neem tree are used to treat pyrexia, headache, ulcer, respiratory disorders, cancer, diabetes, leprosy, malaria, dengue, chicken pox, and dermal complications. The tree is popular for its pharmacological attributes such as hypolipidemic, antifertility, microbicidal, antidiabetic, anti-inflammatory, hepatoprotective, antipyretic, hypoglycemic, insecticidal, nematicidal, antiulcer, antioxidant, neuroprotective, cardioprotective, and antileishmaniasis properties. A. indica is also rich in various phytochemicals for pharmaceuticals such as alkaloids, steroids, flavonoids, terpenoids, fatty acids, and carbohydrates. ${ }^{[5]}$

The chemopreventive and anticancer therapeutic efficacy of $A$. indica fractions and compounds could be explained by multiple cellular and molecular mechanisms, including free radical scavenging, carcinogen-detoxification, DNA repair, cell cycle alteration, programmed cell death (apoptosis) and autophagy, immune surveillance, anti-inflammatory, anti-angiogenic, anti-invasive, and anti-metastatic activities as well as their ability to modulate several dysregulated oncogenic signaling pathways. ${ }^{[6]}$

\section{Literature review}

Few bibliometric studies made a bibliometric assessment of Azadirachta research in the past. Thirumagal and Ramesh ${ }^{[7]}$ explored global neem research (392 papers) during 2006-2010. It used PubMed database and focused on various aspects: growth rate, authorship pattern-number of authors, productivity and degree of collaboration, bibliographic format, language-wise and country-wise distribution, identification of core journals using Bradford law, and depicting a clustering view of neem research. Singh ${ }^{[8]}$ examined global Azadirachta research (1198 papers) during 1901-2014. It also used PubMed and focused on chronological growth of literature, authorship pattern and author productivity, fitness of distribution of papers to Bradford's law of scattering, country-wise contribution and identification of core journals. Vijayakumar and Shehbaz ${ }^{[0]}$ studied the authorship pattern of $A$. indica literature, which revealed that collaborative research is more favored than the solo research with a degree of collaboration as 0.94 . Similar bibliometric studies have been published on other individual medicinal plants such as Aloe Vera ${ }^{[10]}$ Curcuma longa $^{[11]}$ Glycyrrbiza glabra, ${ }^{[12]}$ Ocimum Santum, ${ }^{[13]}$ Pheonix dactylifera ${ }^{[14]}$ Tinospora cordifolia, ${ }^{[15]}$ and Phyllanthis emblica. ${ }^{[16]}$

\section{Objectives}

The study examines global $A$. indica research performance, in terms of quantitative and qualitative indicators during 22 years (1997-2016), based on publications indexed in the Scopus database. Its objectives are as follows: (i) to study the growth and distribution of global literature on A. indica, (ii) to examine the scientometric profile and characteristics of the 10 most productive countries, 25 most productive organizations, and to 25 most productive authors, (iii) to study the distribution of publication output by broad subject areas and identification of significant keywords, (iv) to identify the medium of communication and the bibliographic characteristics of global highly cited publications on $A$. indica.

\section{METHODOLOGY}

The top 10 most productive countries global publications on $A$. indica were sourced from Scopus international database (http://www.scopus.com), using two keywords "Azadirachta indica" or "neem" for the years 1997-2016. The TITLE-ABS-KEY (as shown in search string below) tag was searched for the two keywords restricting the hit to the period 1997-2016 in "date range" tag. The 
statement becomes the main search string. The main search string was further restricted to individual 10 countries in "country" tag one by one for obtaining publication data of these countries. On further restricting global search string by "subject area tag," "country tag," "source title tag," "journal title name" and "affiliation tag," statistics on the distribution of publications by subject, collaborating countries, author-wise, organization-wise and journal-wise, etc., were obtained. Citation data were obtained from the date of publication to January 25, 2018. Select bibliometric indicators have been used to study the performance of global $A$. indica research.

\section{TITLE-ABS-KEY (Azadirachta indica or neem) AND PUBYEAR > 1996 AND PUBYEAR < 2017.}

\section{Analysis}

The total research output of the world in the field of $A$. indica cumulated to 4900 publications in 20 years during 1997-2016. The $A$. indica annual global research output increased from 95 in the year 1997 to 321 publications in the year 2016, registering $7.61 \%$ growth per annum. The cumulative world output in A. indica research in 10 years 1997-2006 increased from 1375 to 3525 publications during succeeding 10-year period 2007-2016, registering $156.36 \%$ growth. The citation impact of global publications on $A$. indica in 20 years averaged to 13.91 citations per publication (CPP) during 1997-2016; ten-yearly impact averaged to $25.98 \mathrm{CPP}$ for the period 1997-2006, which sharply declined to 9.21 CPP in the succeeding 5-year 2007-2016 [Table 1].

Of the total global publications output, $89.53 \%$ (4387) appeared as articles, 6.35\% (311) as reviews, 2.29\% (112) as conference papers and the rest below 1\%: book chapters $(0.47 \%)$, letters and notes $(0.37 \%$ each), short surveys $(0.22 \%)$, editorial $(0.14 \%)$, erratum $(0.12 \%)$, conference reviews $(0.06 \%)$, articles in press $(0.04 \%)$, and book and retracted $(0.02 \%$ each $)$.

Top 10 most productive countries in Azadivachta indica research

The global research output in the field of $A$. indica research had originated from as many as 112 countries in the world during 1997-2016, of which, 64 published 1-10 papers each in 20 years, 31 countries $11-50$ papers each, 9 countries 51-100 papers each, 7 countries 101-300 papers each, and 1 country 2621 papers. The top 10 most productive countries in A. indica research contributed 84-2461 publications each during 1997-2016 [Table 2]. The top 10 most productive countries in $A$. indica research accounted for $86.22 \%$ global publication share and $85.81 \%$ citation share during 1997-2016. Their ten-yearly output accounted for $85.89 \%$
Table 1: World output in Azadirachta indica research, 19972016

\begin{tabular}{lccccccc}
\hline \multirow{2}{*}{$\begin{array}{l}\text { Publication } \\
\text { period }\end{array}$} & \multicolumn{3}{c}{ World } & Publication & \multicolumn{3}{c}{ World } \\
\cline { 2 - 5 } \cline { 6 - 8 } & TP & TC & CPP & period & TP & TC & CPP \\
\hline 1997 & 95 & 1463 & 15.40 & 2009 & 325 & 5314 & 16.35 \\
1998 & 107 & 2151 & 20.10 & 2010 & 392 & 4105 & 10.47 \\
1999 & 98 & 2402 & 24.51 & 2011 & 441 & 4136 & 9.38 \\
2000 & 118 & 2552 & 21.63 & 2012 & 419 & 3617 & 8.63 \\
2001 & 96 & 2597 & 27.05 & 2013 & 361 & 2982 & 8.26 \\
2002 & 122 & 3895 & 31.93 & 2014 & 402 & 1992 & 4.96 \\
2003 & 158 & 3716 & 23.52 & 2015 & 351 & 1156 & 3.29 \\
2004 & 175 & 6221 & 35.55 & 2016 & 321 & 623 & 1.94 \\
2005 & 183 & 4660 & 25.46 & $1997-2006$ & 1375 & 35,719 & 25.98 \\
2006 & 223 & 6062 & 27.18 & $2007-2016$ & 3525 & 32,459 & 9.21 \\
2007 & 237 & 4406 & 18.59 & $1997-2016$ & 4900 & 68,178 & 13.91 \\
2008 & 276 & 4128 & 14.96 & & & & \\
\hline TP: Total papers, TC: Total citations, CPP: Citations per paper &
\end{tabular}

global publication share during 1997-2006 which increased to $86.35 \%$ during succeeding 10-year period 2007-2016. Country-wise, the global publication share of top 15 countries varied widely $1.71 \%-53.49 \%$ during $1997-2016$, with India accounting for the highest publication share $(53.49 \%)$, followed by Brazil (6.12\%), USA (6.02\%), Nigeria (5.57\%), Pakistan (4.71\%), and other countries, namely UK, Germany, China, Egypt, and Malaysia (from 1.71\% to $2.45 \%$ ) during 1997-2016. The global publication share registered an increasing publication share varying from $0.45 \%$ to $3.01 \%$ in six countries, namely Pakistan, Egypt, Nigeria, India, Malaysia, and China, as against decrease from $0.39 \%$ to $4.57 \%$ in four countries, namely Brazil, German, UK, and USA in 10 years (1997-2006 and 2007-2016). Only three of the top 10 countries scored relative citation index above the world average of 1.00: UK (1.95), USA (1.71), and Germany (1.42) during 1997-2016. India has though emerged as one of the world leaders in $A$. indica research, its performance in terms of relative citation index (0.96) has below the world average.

\section{International collaboration}

The international collaborative output of top 10 most productive countries in $A$. indica research as a national share in the country-wise output varied widely from $7.97 \%$ to $65.09 \%$, with an average share of $17.44 \%$ during $1997-2016$. The highest international collaborative publication share comes from Germany $(65.09 \%)$, followed by UK $(60.0 \%)$, USA (56.95\%), Egypt (44.44\%), Malaysia (39.29\%), China (25.91\%), Pakistan (19.05\%), Nigeria (16.12\%), Brazil (10.33\%), and India (7.97\%) during 1997-2016. Most surprisingly, India's international collaborative share in its national output in $A$. indica research has been comparatively small and lowest, $7.97 \%$.

\section{Subject-wise distribution of research output}

The global $A$. indica research output published during 1997-2016 is distributed across eight sub-fields (as identified 
in Scopus database classification), with agricultural and biological sciences accounting for the highest publications share $(48.41 \%)$, followed by pharmacology, toxicology and pharmaceutics (22.04\%), biochemistry, genetics, and molecular biology $(17.35 \%)$, medicine $(16.80 \%)$, environmental science (13.39\%), and other three sub-fields contribution varying from $4.90 \%$ to $8.22 \%$ during 1997-2016. Its activity index, which computes change in research activity in the discipline over time 1997-2006 to 2007-2016 (world average activity index of a given subject is taken as 100), witnessed increase in pharmacology, toxicology, and pharmaceutics (from 84.47 to 106.06), biochemistry, genetics, and molecular biology (from 95.17 to 101.88), medicine (from 72.31 to 110.80), immunology and microbiology (from 85.77 to 105.55), and veterinary science (from 81.67 to 107.15), as against decrease in agricultural and biological sciences (from 111.99 to 95.32), environmental science (from 124.4 to 90.48), and chemistry (from 111.8 to 95.40) from 1997-2006 to 2007-2016. Chemistry, among various subjects registered the highest citations impact per paper of $19.51 \mathrm{CPP}$, followed by immunology and microbiology (17.80), pharmacology, toxicology, and pharmaceutics (17.38), medicine (15.55), environmental science (15.49), biochemistry, genetics, and molecular biology (14.57), veterinary science (11.25), and agricultural and biological sciences (10.61) during 1997-2016 [Table 3].

\section{Profile of Top 25 Most Productive Global Organizations} Eight hundred and forty-eight organizations participated in global research on A. indica during 1997-2016, of which 715 organizations contributed $1-10$ papers each, 85 organizations 11-20 papers each, 41 organizations 21-50 papers each, and 5 organizations 51-64 papers each.

The productivity of top 25 most productive global organizations in $A$. indica research varied from 27 to 64 publications and together they contributed $20.65 \%$ (1012) publication share and $22.43 \%(15,293)$ citation share during 1997-2016. The scientometric profile of these top 25 organizations is presented in Table 4.

- Ten organizations registered publications output greater than the group average of 40.48: Banaras Hindu University, Varanasi, India (64 papers), Indian Agricultural Research Institute, New Delhi, India (63 papers), University of Karachi, Pakistan (60 papers), Annamalai University, India (55 papers), Tamil Nadu Agricultural University, India (51 papers), Indian Veterinary Research Institute, India and King Saud University, Saudi Arabia (49 papers each),

Table 2: Global publication share of top 10 most productive countries in Azadirachta indica during 1997-2016

\begin{tabular}{|c|c|c|c|c|c|c|c|c|c|c|c|}
\hline \multirow{2}{*}{\multicolumn{2}{|c|}{ Serial number Name of the country }} & \multicolumn{3}{|c|}{ Number of papers } & \multicolumn{3}{|c|}{ Share of papers } & \multirow[t]{2}{*}{ TC } & \multirow{2}{*}{\multicolumn{2}{|c|}{$\begin{array}{cc}\text { CPP } & \text { ICP (\%) } \\
1997-2016\end{array}$}} & \multirow[t]{2}{*}{$\mathrm{RCl}$} \\
\hline & & $1997-2006$ & 2007-2016 & $1997-2016$ & $1997-2006$ & 2007-2016 & 1997-2016 & & & & \\
\hline 1 & India & 721 & 1900 & 2621 & 52.44 & 53.90 & 53.49 & 34,917 & 13.32 & $209(7.97)$ & 0.96 \\
\hline 2 & Brazil & 88 & 212 & 300 & 6.40 & 6.01 & 6.12 & 3109 & 10.36 & 31 (10.33) & 0.75 \\
\hline 3 & USA & 128 & 167 & 295 & 9.31 & 4.74 & 6.02 & 7018 & 23.79 & $168(56.95)$ & 1.71 \\
\hline 4 & Nigeria & 60 & 213 & 273 & 4.36 & 6.04 & 5.57 & 2797 & 10.25 & 44 (16.12) & 0.74 \\
\hline 5 & Pakistan & 35 & 196 & 231 & 2.55 & 5.56 & 4.71 & 2449 & 10.60 & 44 (19.05) & 0.76 \\
\hline 6 & U.K. & 62 & 58 & 120 & 4.51 & 1.65 & 2.45 & 3256 & 27.13 & $72(60.00)$ & 1.95 \\
\hline 7 & Germany & 47 & 59 & 106 & 3.42 & 1.67 & 2.16 & 2097 & 19.78 & $69(65.09)$ & 1.42 \\
\hline 8 & China & 25 & 80 & 105 & 1.82 & 2.27 & 2.14 & 1021 & 9.72 & $27(25.71)$ & 0.70 \\
\hline 9 & Egypt & 5 & 85 & 90 & 0.36 & 2.41 & 1.84 & 1016 & 11.29 & $40(44.44)$ & 0.81 \\
\hline 10 & Malaysia & 10 & 74 & 84 & 0.73 & 2.10 & 1.71 & 823 & 9.80 & $33(39.29)$ & 0.70 \\
\hline Total & & 1181 & 3044 & 4225 & 85.89 & 86.35 & 86.22 & 58,503 & 13.85 & $737(17.44)$ & 1.00 \\
\hline $\begin{array}{l}\text { World } \\
\text { Share of } 10 \text { cour }\end{array}$ & Intries in world total & 1375 & 3525 & 4900 & & & & $\begin{array}{c}68,178 \\
85.81\end{array}$ & 13.91 & & \\
\hline
\end{tabular}

TC: Total citations, CPP: Citations per paper, ICP: International collaborative papers, RCI: Relative citation index

Table 3: Subject-wise breakup of global publications in Azadirachta indica research during 1997-2016

\begin{tabular}{|c|c|c|c|c|c|c|c|c|c|}
\hline \multirow[t]{2}{*}{ Serial number } & \multirow[t]{2}{*}{ Subject* } & \multicolumn{3}{|c|}{ Number of papers (TP) } & \multicolumn{2}{|c|}{ Activity index } & TC & CPP & TP (\%) \\
\hline & & $1997-2006$ & $2007-2016$ & $1997-2016$ & $1997-2006$ & 2007-2016 & \multicolumn{3}{|c|}{ 2007-2016 } \\
\hline 1 & Agricultural and biological sciences & 747 & 1630 & 2377 & 111.99 & 95.32 & 25215 & 10.61 & 48.51 \\
\hline 2 & Pharmacology, toxicology and pharmaceutics & 256 & 824 & 1080 & 84.47 & 106.06 & 18767 & 17.38 & 22.04 \\
\hline 3 & Biochemistry, genetics and molecular biology & 227 & 623 & 850 & 95.17 & 101.88 & 12387 & 14.57 & 17.35 \\
\hline 4 & Medicine & 167 & 656 & 823 & 72.31 & 110.80 & 12798 & 15.55 & 16.80 \\
\hline 5 & Environmental science & 229 & 427 & 656 & 124.40 & 90.48 & 10159 & 15.49 & 13.39 \\
\hline 6 & Immunology and microbiology & 97 & 306 & 403 & 85.77 & 105.55 & 7172 & 17.80 & 8.22 \\
\hline 7 & Chemistry & 112 & 245 & 357 & 111.80 & 95.40 & 6965 & 19.51 & 7.29 \\
\hline 8 & Veterinary science & 55 & 185 & 240 & 81.67 & 107.15 & 2700 & 11.25 & 4.90 \\
\hline World output & & 1375 & 3525 & 4900 & & & & & \\
\hline
\end{tabular}

There is overlapping of literature covered under various subjects

TP: Total papers, TC: Total citations, CPP: Citations per paper 
Table 4: Scientometric profile of top 25 most productive global organizations in Azadirachta indica research during $1997-2016$

\begin{tabular}{|c|c|c|c|c|c|c|c|}
\hline Serial number & Name of the organization & TP & TC & CPP & $\mathrm{HI}$ & ICP (\%) & $\mathrm{RCl}$ \\
\hline 1 & Banaras Hindu University, Varanasi, India & 64 & 1601 & 25.02 & 21 & $9(14.06)$ & 1.80 \\
\hline 2 & Indian Agricultural Research Institute, New Delhi, India & 63 & 865 & 13.73 & 16 & $5(7.94)$ & 0.99 \\
\hline 3 & University of Karachi, Pakistan & 60 & 469 & 7.82 & 2 & $5(8.33)$ & 0.56 \\
\hline 4 & Annamalai University, India & 55 & 1472 & 26.76 & 24 & $1(1.82)$ & 1.92 \\
\hline 5 & Tamil Nadu Agricultural University, India & 51 & 410 & 8.04 & 11 & $4(7.84)$ & 0.58 \\
\hline 6 & Indian Veterinary Research Institute, India & 49 & 664 & 13.55 & 14 & $3(6.12)$ & 0.97 \\
\hline 7 & King Saud University, Saudi Arabia & 49 & 884 & 18.04 & 17 & 39 (79.59) & 1.30 \\
\hline 8 & UNESP-Universidade EStadual Paulista, Brazil & 48 & 414 & 8.63 & 12 & $2(4.17)$ & 0.62 \\
\hline 9 & University of Agriculture, Faisalabad, Pakistan & 43 & 964 & 22.42 & 12 & $10(23.26)$ & 1.61 \\
\hline 10 & Federal University of Viscosa, Brazil & 41 & 289 & 7.05 & 10 & $6(14.63)$ & 0.51 \\
\hline 11 & Bharathiar University, Coimbatore, India & 40 & 1164 & 29.10 & 17 & $24(60.00)$ & 2.09 \\
\hline 12 & Panjab University, Chandigarh, India & 37 & 339 & 9.16 & 13 & $2(5.41)$ & 0.66 \\
\hline 13 & Chittaranjan National Cancer Institute, Kolkata, India & 37 & 683 & 18.46 & 17 & $8(21.62)$ & 1.33 \\
\hline 14 & University of Ibadan, Nigeria & 36 & 554 & 15.39 & 12 & $7(19.44)$ & 1.11 \\
\hline 15 & University of Mysore, India & 36 & 308 & 8.56 & 9 & $2(5.56)$ & 0.62 \\
\hline 16 & Universidade de Sao Paulo-USP, Brazil & 35 & 247 & 7.06 & 9 & $3(8.57)$ & 0.51 \\
\hline 17 & Indian Institute of Technology, New Delhi & 34 & 473 & 13.91 & 12 & $6(17.65)$ & 1.00 \\
\hline 18 & Ahmadu Bello University, Nigeria & 32 & 205 & 6.41 & 8 & $3(9.38)$ & 0.46 \\
\hline 19 & Vellore Institute of Technology, India & 31 & 558 & 18.00 & 11 & $3(9.68)$ & 1.29 \\
\hline 20 & University of Agricultural Sciences, Bangalore, India & 30 & 103 & 3.43 & 5 & $1(3.33)$ & 0.25 \\
\hline 21 & Arid Forestry Research Institute, Jodhpur, India & 29 & 140 & 4.83 & 6 & $1(3.45)$ & 0.35 \\
\hline 22 & Aligarh Muslim University, India & 29 & 900 & 31.03 & 12 & $2(6.90)$ & 2.23 \\
\hline 23 & Universidade Federal Rural de Pernambuco, Brazil & 28 & 169 & 6.04 & 8 & $1(3.57)$ & 0.43 \\
\hline 24 & Central Arid Zone Research Institute, Jodhpur, India & 28 & 684 & 24.43 & 8 & $1(3.57)$ & 1.76 \\
\hline 25 & Wageningen University and Research Centre, Netherlands & 27 & 734 & 27.19 & 13 & $23(85.19)$ & 1.95 \\
\hline \multicolumn{2}{|c|}{ Total of 25 organizations } & 1012 & 15293 & 15.11 & 11.96 & $171(16.90)$ & 1.09 \\
\hline \multicolumn{2}{|l|}{ Total of world } & 4900 & 68178 & 13.91 & & & \\
\hline \multicolumn{2}{|c|}{ Share of top 25 organizations in world output } & 20.65 & 22.43 & & & & \\
\hline
\end{tabular}

TP: Total papers, TC: Total citations, CPP: Citations per paper, HI: h-index, ICP: International collaborative papers, RCI: Relative citation index

UNESP-Universidade Estadual Paulista, Brazil (48 papers), University of Agriculture, Faisalabad, Pakistan (43 papers) and Federal University of Viscosa, Brazil (41 papers) during 1997-2016

- Eleven organizations registered impact and relative citation index above the group average of $15.11 \mathrm{CPP}$ and 1.09 during 1997-2016: Aligarh Muslim University, India (31.03 and 2.23), Bharathiar University, Coimbatore, India (29.10 and 2.09), Wageningen University and Research Centre, Netherlands (27.19 and 1.95), Annamalai University, India (26.76 and 1.92), Banaras Hindu University, Varanasi, India (25.02 and 1.80), Central Arid Zone Research Institute, Jodhpur, India (24.43 and 1.76), University of Agriculture, Faisalabad, Pakistan (22.42 and 1.61), Chittaranjan National Cancer Institute, Kolkata, India (18.46 and 1.33), King Saud University, Saudi Arabia (18.04 and 1.30), Vellore Institute of Technology, India (18.0 and 1.29) and University of Ibadan, Nigeria (19.44 and 1.11) during 1996-2016

- Seven organizations contributed international collaborative publications share above the group average of $16.90 \%$ : Wageningen University and Research Centre, Netherlands (85.19\%), King Saud University, Saudi Arabia (79.59\%), Bharathiar University, Coimbatore, India (60.0\%), University of Agriculture, Faisalabad, Pakistan (23.26\%), Chittaranjan
National Cancer Institute, Kolkata, India (21.62\%), University of Ibadan, Nigeria (19.44\%), Indian Institute of Technology, New Delhi (17.65\%) during 1997-2016.

\section{Profile of top 25 most productive authors}

A total of 1589 authors participated in global research on $A$. indica during 1997-2016, of which 1414 authors contributed $1-5$ papers each, 141 authors 6-10 papers each, 29 authors 11-20 papers each, and 5 authors $21-37$ papers each.

The research productivity in the field of $A$. indica research of top 25 most productive authors varied from 13 to 37 publications. Together they contributed 8.92\% (437) global publication share and $12.66 \%$ (8628) citation share during 1997-2016. The scientometric profile of these 20 authors is presented in Table 5 .

- Seven authors registered publications output above the group average of 17.48: R. Baral (37 papers), A. Bose (31 papers), S. Nagini (30 papers), A. Koul, K. Murugan and B. S. Siddiqui (20 papers each), A. K. Srivastava (18 papers) during 1997-2016

- Ten authors registered impact and relative citation index above the group average of 19.74 CPP and 1.42: K. G. Bhattacharyya (52.15 and 3.75), S. Nagini (38.40 and 2.76), V. C. Verma (37.77 and 2.72), K. Murugan (29.29 and 2.11), N. Chandrasekaran (29.08 and 2.09), 
Table 5: Scientometric profile of top 25 most productive authors in Azadirachta indica research during 1997-2016

\begin{tabular}{|c|c|c|c|c|c|c|c|c|}
\hline Serial number & Name of the author & Affiliation of the author & TP & TC & CPP & $\mathrm{HI}$ & ICP (\%) & $\mathrm{RCl}$ \\
\hline 1 & R. Baral & Chittranjan National Cancer Institute, Kolkata, India & 37 & 683 & 18.46 & 17 & $8(21.62)$ & 1.33 \\
\hline 2 & A. Bose & Chittranjan National Cancer Institute, Kolkata, India & 31 & 477 & 15.39 & 15 & $8(25.81)$ & 1.11 \\
\hline 3 & S. Nagini & Annamalai University, India & 30 & 1152 & 38.40 & 9 & $0(0.00)$ & 2.76 \\
\hline 4 & A. Koul & Panjab University, Chandigarh, India & 24 & 279 & 11.63 & 11 & $1(4.17)$ & 0.84 \\
\hline 5 & K. Murugan & Bharathiar University, India & 24 & 703 & 29.29 & 15 & $21(87.50)$ & 2.11 \\
\hline 6 & B.S. Siddiqui & University of Karachi, Pakistan & 20 & 306 & 15.30 & 11 & $0(0.00)$ & 1.10 \\
\hline 7 & A.K. Srivastava & Indian Institute of Technology, New Delhi, India & 18 & 317 & 17.61 & 10 & $1(5.56)$ & 1.27 \\
\hline 8 & G. Gopalakrishnan & SPIC Science Foundation, Chennai, India & 17 & 222 & 13.06 & 8 & $3(17.65)$ & 0.94 \\
\hline 9 & F. Abdel-Ghaffar & Cairo University, Egypt & 16 & 441 & 27.56 & 13 & 15 (93.75) & 1.98 \\
\hline 10 & M.R. Forim & Universidade Federal de Sao Carlos, Brazil & 15 & 107 & 7.13 & 7 & $1(6.67)$ & 0.51 \\
\hline 11 & K. Sarkar & National Cancer Research Institute, Kolkata, India & 15 & 280 & 18.67 & 12 & $6(40.00)$ & 1.34 \\
\hline 12 & V.R.B. Sastry & $\begin{array}{l}\text { National Institute of Animal Nutrition and Physiology, } \\
\text { Bangalore, India }\end{array}$ & 15 & 67 & 4.47 & 4 & 2 (13.33) & 0.32 \\
\hline 13 & J.D. Vendramim & ESALQ/USP, Brazil & 15 & 137 & 9.13 & 8 & $0(0.00)$ & 0.66 \\
\hline 14 & S. Barik & National Cancer Research Institute, India & 14 & 128 & 9.14 & 7 & $6(42.86)$ & 0.66 \\
\hline 15 & X.M. Peng & $\begin{array}{l}\text { Research Institute of Resource Insects of Chinese Academy } \\
\text { of Forestry, China }\end{array}$ & 14 & 12 & 0.86 & 2 & $0(0.00)$ & 0.06 \\
\hline 16 & H.M. Poehling & Kasetsart University, Germany & 14 & 191 & 13.64 & 9 & $6(42.86)$ & 0.98 \\
\hline 17 & Y.X. Zheng & $\begin{array}{l}\text { Research Institute of Resource Insects of Chinese Academy } \\
\text { of Forestry, China }\end{array}$ & 14 & 21 & 1.50 & 2 & $0(0.00)$ & 0.11 \\
\hline 18 & K.G. Bhattacharyya & Guwahati University, India & 13 & 678 & 52.15 & 8 & $0(0.00)$ & 3.75 \\
\hline 19 & N. Chandrasekaran & Vellore Institute of Technology, India & 13 & 378 & 29.08 & 7 & $2(15.38)$ & 2.09 \\
\hline 20 & S. Ignacimuthu & Loyola College, Chennai, India & 13 & 359 & 27.62 & 8 & $2(15.38)$ & 1.99 \\
\hline 21 & Z. Iqbal & University of Agriculture, Faisalabad, Pakistan & 13 & 290 & 22.31 & 9 & $2(15.38)$ & 1.60 \\
\hline 22 & H. Mehlhorn & Heinnch Heine University, Germany & 13 & 341 & 26.23 & 11 & $3(23.08)$ & 1.89 \\
\hline 23 & A. Mukherjee & Vellore Institute of Technology, India & 13 & 378 & 29.08 & 7 & $2(15.38)$ & 2.09 \\
\hline 24 & G. Suresh & SPIC Science Foundation, Chennai, India & 13 & 190 & 14.62 & 8 & $3(23.08)$ & 1.05 \\
\hline 25 & V.C. Verma & Banaras Hindu University, India & 13 & 491 & 37.77 & 9 & 7 (53.85) & 2.72 \\
\hline \multicolumn{3}{|c|}{ of 25 authors } & 437 & 8628 & 19.74 & 9.08 & $99(22.65)$ & 1.42 \\
\hline \multicolumn{3}{|l|}{ Total of world } & 4900 & 68,178 & 13.91 & & & \\
\hline \multicolumn{3}{|c|}{ Share of top 25 authors in world total output } & 8.92 & & & & & \\
\hline
\end{tabular}

TP: Total papers, TC: Total citations, CPP: Citations per paper, HI: h-index, ICP: International collaborative papers, RCI: Relative citation index

A. Mukherjee (29.08 and 2.09), S. Ignacimuthu (27.62 and 1.99), F. Abdel-Ghaffar (27.56 and 1.98), H. Mehlhorn (26.23 and 1.89), and Z. Iqbal (22.31 and 1.60) during 1997-2016

- Nine authors contributed international collaborative publications share above the group average of $22.65 \%$ of all authors: F. Abdel-Ghaffar (93.75\%), K. Murugan $(87.50 \%)$, V. C. Verma $(53.85 \%)$, S. Barik (42.86\%),H.M. Poehling (42.86\%), K. Sarkar(40.0\%), A. Bose (25.81\%), H. Mehlhorn (23.08\%), and G. Suresh (23.08\%) during 1997-2016.

\section{Medium of research communication}

Of the total world output on $A$. indica research, $97.14 \%$ (4387) appeared in journals, $1.55 \%$ (76) in book series, $0.51 \%(25)$ in trade publications, and $0.31 \%(15)$ in conference proceedings during 1997-2016. 4387 journal papers appeared in 959 journals, of which 770 journals published $1-5$ papers each, 104 journals $6-10$ papers each, 50 journals $11-20$ papers each, 29 journals $21-50$ papers each, 3 journals $51-100$ papers each, and 2 journals 101-134 papers each during 1997-2016.

The top 20 most productive journals reported 29-134 papers each on $A$. indica research; together they accounted for $43.63 \%$ (1037 papers) share of total $A$. indica output published in journals during 1997-2016. A. indica research being reported increasingly in journals is gradually becoming a trend; for example, the top 20 most productive journals in 10 years has shown increase in their $A$. indica output from $18.63 \%$ to $76.31 \%$ share between $1997-2006$ and $2007-2016$. The top ranking journal is Journal of Ethnopharmacology (with 134 papers), followed by Pestology (130 papers), Archives of Phytopathology and Plant Protection (85 papers), Indian Journal of Agricultural Sciences (74 papers), Journal of Biopesticides (62 papers), etc., during 1997-2016 [Table 6].

\section{Significant keywords}

Around 44 significant keywords having the potential to identify comparative research trends in $A$. indica research studies including pharmacological properties and medicinal uses were discovered from the global literature on $A$. indica. These keywords are listed in Table 7 in the decreasing order of the frequency of their occurrence in the literature during 1997-2016.

\section{Highly cited papers}

Seventy-eight highly cited papers in $A$. indica research were identified each having 100-1441 citations (50 papers each in citation range 100-199, 23 papers each in 200-499 
Table 6: Top 20 most productive journals in Azadirachta indica research during 1997-2016

\begin{tabular}{|c|c|c|c|c|}
\hline \multirow[t]{2}{*}{ Serial number } & \multirow[t]{2}{*}{ Name of the journal } & \multicolumn{3}{|c|}{ Number of papers } \\
\hline & & $2007-2011$ & 2012-2016 & 2007-2016 \\
\hline 1 & Journal of Ethnopharmacology & 44 & 90 & 134 \\
\hline 2 & Pestology & 52 & 78 & 130 \\
\hline 3 & Archives of Phytopathology and Plant Protection & 4 & 81 & 85 \\
\hline 4 & Indian Journal of Agricultural Sciences & 24 & 50 & 74 \\
\hline 5 & Journal of Biopesticides & 0 & 62 & 62 \\
\hline 6 & International Journal of Pharma and Bio Sciences & 0 & 49 & 49 \\
\hline 7 & Parasitology Review & 2 & 41 & 43 \\
\hline 8 & Research Journal of Pharmaceutical Biological and Chemical Sciences & 0 & 42 & 42 \\
\hline 9 & Crop Protection & 17 & 23 & 40 \\
\hline 10 & International Journal of Pharmaceutical Sciences Review and Research & 0 & 38 & 38 \\
\hline 11 & International Journal of Pharmacy and Pharmaceutical Sciences & 0 & 38 & 38 \\
\hline 12 & Pakistan Journal of Botany & 3 & 35 & 38 \\
\hline 13 & Phytotherapy Research & 24 & 12 & 36 \\
\hline 14 & Journal of Economic Entomology & 24 & 11 & 35 \\
\hline 15 & Phytoparasitica & 0 & 35 & 35 \\
\hline 16 & African Journal of Biotechnology & 6 & 28 & 34 \\
\hline 17 & Ecology Environment and Conservation & 7 & 26 & 33 \\
\hline 18 & Indian Journal of Animal Sciences & 19 & 14 & 33 \\
\hline 19 & Asian Journal of Microbiology Biotechnology and Environment Sciences & 12 & 17 & 29 \\
\hline 20 & Current Science & 13 & 16 & 29 \\
\hline \multicolumn{2}{|c|}{ Total of 20 journals } & 251 & 786 & 1037 \\
\hline \multicolumn{2}{|c|}{ Total global journal output } & 1347 & 1030 & 2377 \\
\hline \multicolumn{2}{|c|}{ Share of top 20 journals in global journal output } & 18.63 & 76.31 & 43.63 \\
\hline
\end{tabular}

Table 7: List of significant keywords in literature on Azadirachta indica research during 1997-2016

\begin{tabular}{llcll}
\hline Serial number & Keyword & Frequency & Serial number & Keyword \\
\hline 1 & A. indica & 3883 & 23 & Drug isolation \\
2 & Neem & 768 & 24 & Bacteria (microorganism) \\
3 & Plant leaf & 720 & 25 & Plant root \\
4 & Medicinal plants & 720 & 26 & Antimicrobial activity \\
5 & Azadirachta & 403 & 27 & Antioxidant activity \\
6 & Chemistry & 323 & 28 & Drug mechanism \\
7 & Drug effect & 320 & 29 & Enzyme activity \\
8 & Insecticide & 309 & 30 & E. coli \\
9 & Neem oil & 309 & 31 & Malaria \\
10 & Herbaceous agent & 278 & 32 & Essential oils \\
11 & Plant seed & 266 & 33 & Terpenes \\
12 & Plant leaves & 260 & 34 & Anti-ineffective agents \\
13 & Phytotherapy & 249 & 35 & Bio-pesticides \\
14 & Drug efficacy & 246 & 36 & Ethno-botany \\
15 & Traditional medicine & 238 & 37 & Pesticides \\
16 & Pest control & 222 & 38 & Flavonoids \\
17 & Phytochemistry & 194 & 39 & E. coli \\
18 & Ant0bacterial activity & 181 & 40 & Anti-fungal activity \\
19 & Drug screening & 181 & 41 & Anti-neoplastic activity \\
20 & Bark & 179 & 42 & Antioxidants \\
21 & Herbal medicine & 169 & 43 & Integrated pest management \\
22 & Diabetes mellitus & 169 & 44 & Insect control
\end{tabular}

A. indica: Azadirachta indica, E. coli: Escherichia coli

citations range, 3 papers each in 500-999 citations range and 2 papers $1000-1441$ citations range each) in 22 years during 1997-16. Seventy-eight papers together cumulated a total of 18498 citations, averaging 237.15 citations per paper. Of the 78 highly cited papers, 45 resulted from the participation of research organizations in their role as stand-alone (noncollaborating) institutional authors and remaining 33 from two or more research organizations working in their role as collaborating partners per paper $(20$ national collaborative and 13 international collaborative).
Among 78 highly cited papers, the largest participation was seen from India (42 papers), followed by the USA (11 papers), UK (7 paper), Canada (5 papers), Brazil, Germany, and Nigeria (3 papers each), Bangladesh, Kenya, and Pakistan (2 papers each), Croatia, Costa Rica, Denmark, Ghana, Hong Kong, Japan, Malaysia, South Africa, South Korea, Spain, Thailand, Tongo, and Uganda (1 paper each). These 78 highly cited papers involved the participation of 242 personal authors and 116 research organizations in total globally. Of the 78 highly cited 
papers, 56 were published as articles, 20 as reviews papers, and 2 as conference papers. These 78 highly cited papers were published in 63 journals, with 11 papers in Journal of Ethnopharmacology, 2 papers each in Biomass and Bioenergy, Chemical Engineering Journal, Food Chemistry, Journal of American Mosquito Control Association and Journal of Hazardous Materials and 1 paper each in 57 other journals.

\section{RESULTS AND CONCLUSION}

Research and publications data on $A$. indica sourced from the Scopus database were analyzed in this study to provide a quantitative and qualitative description of its global research output covering 20 years (1997-2016). The study showed that annual and 10-year cumulative global output of $A$. indica research registered $7.61 \%$ and $156.36 \%$ growth. Its global citation impact averaged to 13.91 citations per paper during 1997-2016, which decreased from 25.98 during 1997-2006 to 9.21 during 2007-2016.

India alone accounted for the highest publication share (53.49\%), followed by Brazil (6.12\%), USA (6.02\%), Nigeria $(5.57 \%)$, Pakistan $(4.71 \%)$, and other countries, namely UK, Germany, China, Egypt, and Malaysia (from $1.71 \%$ to $2.45 \%$ ) during $1997-2016$. The top 10 most productive countries in $A$. indica research together accounted $86.22 \%$ global publication share and $85.81 \%$ citation share during 1997-2016. Their 10-year cumulated global publication share increased from $85.89 \%$ to $86.35 \%$ global publication share during 1997-2006 to 2007-2016. Top ranking developing countries in $A$. indica research dominate in quantity of research, whereas American and western countries in the ranking list dominate more in quality of research. For example, India, Brazil, Nigeria, Pakistan, China, and Egypt mainly from developing countries together accounted for $75.58 \%$ global publication share and citation impact (averaging 12.45 citations per paper) and comparatively the USA, UK, and Germany account for only $10.63 \%$ global share and citation impact (averaging 23.74 citations per paper) during 1997-2016.

The global publication share registered an increasing publication share varying from $0.45 \%$ to $3.01 \%$ in 6 countries namely Pakistan, Egypt, Nigeria, India, Malaysia, and China, as against decrease from $0.39 \%$ to $4.57 \%$ in 4 countries, namely Brazil, German, UK and USA in 10 years period (1997-2006 and 2007-2016). Only three of the top 10 countries scored relative citation index above the world average of 1.0: UK (1.95), USA (1.71) and Germany (1.42) during 1997-2016. The international collaborative publication share of American and western countries in $A$. indica was greater (56.95\%-65.09\% share) compared to that of major developing countries $(7.97 \%-$ $44.44 \%$ share).

Agricultural and biological sciences was the most sought after subject area of $A$. indica research, accounting for $(48.41 \%)$ the highest publications share, followed by pharmacology, toxicology and pharmaceutics (22.04\%), biochemistry, genetics and molecular biology (17.35\%), medicine $(16.80 \%)$, environmental science $(13.39 \%)$ and other three sub-fields contribution varying from $4.90 \%$ to $8.22 \%$ during 1997-2016. Among broad subjects, the research activities registered increase pharmacology, toxicology and pharmaceutics, biochemistry, genetics and molecular biology, medicine, immunology and microbiology, and veterinary science, as against decrease in agricultural and biological sciences, environmental science, and chemistry during 1997-2006 to 2007-2016.

The top 25 most productive research organizations and the authors on $A$. indica research collectively contributed $20.65 \%$ and $8.92 \%$ global publication share and $22.43 \%$ and $112.66 \%$ global citation share, respectively, during 1997-2016. The leading organizations in terms of publication productivity were: Banaras Hindu University, Varanasi, India (64 papers), Indian Agricultural Research Institute, New Delhi, India (63 papers), University of Karachi, Pakistan (60 papers), Annamalai University, India (55 papers), Tamil Nadu Agricultural University, India (51 papers), Indian Veterinary Research Institute, India and King Saud University, Saudi Arabia (49 papers each), UNESP-Universidade Estadual Paulista, Brazil (48 papers), University of Agriculture, Faisalabad, Pakistan (43 papers) and Federal University of Viscosa, Brazil (41 papers) during 1997-2016. The leading organizations in terms of citation impact per paper were Aligarh Muslim University, India (31.03 and 2.23), Bharathiar University, Coimbatore, India (29.10 and 2.09), Wageningen University and Research Centre, Netherlands (27.19 and 1.95), Annamalai University, India (26.76 and 1.92), Banaras Hindu University, Varanasi, India (25.02 and 1.80), Central Arid Zone Research Institute, Jodhpur, India (24.43 and 1.76), University of Agriculture, Faisalabad, Pakistan (22.42 and 1.61), Chittaranjan National Cancer Institute, Kolkata, India (18.46 and 1.33), King Saud University, Saudi Arabia (18.04 and 1.30), Vellore Institute of Technology, India (18.0 and 1.29) and University of Ibadan, Nigeria (19.44 and 1.11) during 1996-2016.

The journals medium accounted for $97.14 \%$ global share in $A$. indica research with top 20 most productive journals accounting for $43.63 \%$ of total publications output in journals during 1997-2016. Journal of Ethnopharmacology 
contributed the largest number of papers (134), followed by Pestology (130 papers), Archives of Phytopathology and Plant Protection (85 papers), Indian Journal of Agricultural Sciences (74 papers), Journal ofBiopesticides (62 papers), etc., during 1997-2016.

Of the total $A$. indica global research output, 78 publications registered high citations, in the range of 100-1441 citations per paper and collectively these highly cited papers received a total of 18498 citations, averaging to 237.15 citations per paper. These 78 highly cited papers involved the participation of 242 personal authors and 116 research organizations in total across globe and were published in 63 journals. The leading journals were Journal of Ethnopharmacology (11 papers), Biomass and Bioenergy, Chemical Engineering Journal, Food Chemistry, Journal of American Mosquito Control Association and Journal of Hazardous Materials (2 papers each) and 1 paper each in 57 other journals.

Conclusively, this research study reveals that developing countries (India, Brazil, Nigeria, Pakistan, China, Egypt, and Malaysia) dominate in $A$. indica search more in terms of quantity of research, whereas western countries (USA, UK, and Germany) dominate instead more in terms of quality of research. It is suggested that the developing countries and India, in particular, need to give higher priority to plant based research and needs to coordinate, monitor and prioritize their $\mathrm{R}$ and $\mathrm{D}$ efforts, with higher investment (both financial and manpower) in $\mathrm{R}$ and $\mathrm{D}$ and increase their international collaboration, with a view to increase their research output and improved research impact.

Financial support and sponsorship

Nil.

\section{Conflicts of interest}

There are no conflicts of interest.

\section{REFERENCES}

1. Gupta SC, Prasad S, Tyagi AK, Kunnumakkara AB, Aggarwal BB. Neem (Azadirachta indica): An Indian traditional panacea with modern molecular basis. Phytomedicine 2017;34:14-20.

2. National Research Council. Neem: A Tree for Solving Global Problems. Washington, DC; National Academy Press; 1992. p. 140.

3. Brahmachari G. Neem - An omnipotent plant: A retrospection. Chembiochem 2004;5:408-21.

4. Subapriya R, Nagini S. Medicinal properties of neem leaves: A review. Curr Med Chem Anticancer Agents 2005;5:149-6.

5. Saleem S, Muhammad G, Hussain MA, Bukhari SN. A comprehensive review of phytochemical profile, bioactives for pharmaceuticals, and pharmacological attributes of Azadirachta indica. Phytother Res 2018;32:1241-72.

6. Patel SM, Nagulapalli Venkata KC, Bhattacharyya P, Sethi G, Bishayee A. Potential of neem (Azadirachta indica L.) for prevention and treatment of oncologic diseases. Semin Cancer Biol 2016;40-41:100-15.

7. Thirumagal A, Ramesh S. Quantitative analysis of neem research using Bibexel. SRELS J Inf Manag 2014;51:171-6.

8. Singh N. Scientific output on Adirachta indica (Neem): A bibliometric study. SRELS J Inf Manag 2016;53:479-85.

9. Vijayakumar M, Shehbaz HN. Authorship trends in Adirachta indica literature: A bibliometric study. SRELS J Inf Manag 2002;39:445-55.

10. Gupta BM, Mueen AK, Dhawan SM, Gupta RG. Aloe vera (medicinal plant) research: A scientometric assessment of global publications output during 2007-16. Pharmacogn J 2018;10:1-8.

11. Mueen AK, Gupta BM, Gupta R. Curcuma longa (medicinal plant) research: A scientometric assessment of global publications output during 1997-2016. Pharmacogn J 2018;10:998-1006.

12. Gupta BM, Mueen AK, Gupta RG. Glycyrrbiza glabra (medicinal plant) research: A scientometric assessment of global publications output during 1997-2016. Pharmacogn J 2018;10:1067-75.

13. Gupta BM, Gupta R, Agarwal A, Goel S. Ocimum Santum (medicinal plant) research: A scientometric assessment of global publications output during 2008-17. Int J Inf Dissem Technol 2018;8:67-73.

14. Ibrahim A, Mueen KK, Gupta BM. Global research output on date palm (Pheonix dactylifera): A 12 years scientometrics perspective. Scientometrics 2014;98:157-71.

15. Gupta BM, Mueen AK, Gupta RG. Global research on Tinospora cordifolia (medicinal plant) with special reference to India: A scientometric assessment publications output during 2001-16. Int J Pharmacogn Chin Med 2018;2:1-11.

16. Gupta BM, Dhawan SM, Gupta R. Phyllanthis emblica (medicinal plant) research: A scientometric assessment of global publications output during 2008-17. EC Pharmacol Toxicol 2019;7:18-28. 